\title{
Article \\ Clinical and Functional Predictors of Response to a Comprehensive Pulmonary Rehabilitation in Severe Post-COVID-19 Patients
}

\author{
Marc Spielmanns ${ }^{1,2, *,+} \mathbb{D}^{D}$, Melissa Masha Buelow ${ }^{1,2,+}$, Anna Maria Pekacka-Egli ${ }^{1,3}$, Mikis Cecon ${ }^{1}$, \\ Sabine Spielmanns ${ }^{1}$, Wolfram Windisch ${ }^{2,4} \mathbb{D}$ and Matthias Hermann ${ }^{5}$ (D)
}

Citation: Spielmanns, M.; Buelow, M.M.; Pekacka-Egli, A.M.; Cecon, M.; Spielmanns, S.; Windisch, W.; Hermann, M. Clinical and Functional Predictors of Response to a Comprehensive Pulmonary Rehabilitation in Severe Post-COVID-19 Patients. Microorganisms 2021, 9, 2452. https:// doi.org/10.3390/microorganisms9122452

Academic Editors: Daria Bortolotti and Francesca Caccuri

Received: 24 October 2021

Accepted: 26 November 2021

Published: 28 November 2021

Publisher's Note: MDPI stays neutral with regard to jurisdictional claims in published maps and institutional affiliations.

Copyright: (c) 2021 by the authors. Licensee MDPI, Basel, Switzerland. This article is an open access article distributed under the terms and conditions of the Creative Commons Attribution (CC BY) license (https:// creativecommons.org/licenses/by/ $4.0 /)$.
1 Pulmonary Medicine and Sleep Medicine Center, Zurich RehaCenter Klinik Wald, CH-8636 Wald, Switzerland; melissa.buelow@gmx.de (M.M.B.); annamaria.pekacka@zhreha.ch (A.M.P.-E.); mikis.cecon@zhreha.ch (M.C.); sabine.spielmanns@zhreha.ch (S.S.)

2 Department of Pulmonary Medicine, Faculty of Health, University Witten-Herdecke, D-58455 Witten, Germany; windischw@kliniken-koeln.de

3 Neurological Rehabilitation, Zurich RehaCenter Klinik Wald, CH-8636 Wald, Switzerland

4 Department of Pneumology, Cologne Merheim Hospital, Kliniken der Stadt Koeln GmbH, D-51109 Koeln, Germany

5 Department of Cardiology, University Heart Centre, University Hospital Zurich, CH-8006 Zurich, Switzerland; matthias.hermann@usz.ch

* Correspondence: marc.spielmanns@zhreha.ch; Tel.: +41-55-256-6111

+ M.S. and M.M.B. contributed equally to the preparation of the manuscript.

Abstract: Background: Pulmonary rehabilitation (PR) following severe and very severe COVID-19 infection is known to be effective, according to typical assessments. However, not all patients benefit from PR to the same extent. This analysis aimed to identify the impact of different factors on PR outcomes in post-COVID-19 patients. Methods: This prospective observational study included 184 post-COVID-19 patients. The achievement of the predicted reference walking distance (6 min walking distance (6-MWD)) served as a parameter with which to identify responders and non-responders to PR. Several parameters (e.g., Functional Independent Measurement (FIM); pulmonary function testing (Forced Vital Capacity, FVC); 6MWD) were assessed in order to estimate their impact on PR success. Logistic regression models and classification and regression trees were used for multivariate analysis. Results: A total of 94 patients (51\%) reached their reference 6MWD by the end of PR. FVC (0.95 (0.93-0.97)), 6MWD at admission (0.99 (0.99-1.00)), and FIM motoric (0.96 (0.93-0.99)) correlated with the risk not reaching the reference distance. The most important variable was the 6MWD at admission. Classification and regression tree identified 6MWD $\geq 130 \mathrm{~m}$ at admission and FVC predicted of $>83 \%$ as the strongest predictor for reaching predicted 6-MWD. Conclusion: Post-COVID19 patients with lower 6MWD, lower motoric FIM scores and lower FVC at admission have a high risk of not reaching their target values of physical performance despite intensive rehabilitation. As well as identifying them, it is of utmost importance to develop optimal PR concepts for these patients.

Keywords: COVID-19; pulmonary rehabilitation; FIM; 6-MWD; FVC

\section{Introduction}

Pulmonary rehabilitation (PR), as a comprehensive intervention of exercise training, education, and behavior change, has positive effects on the progress of various pulmonary diseases, particularly for patients with chronic obstructive pulmonary disease (COPD) [1,2] Even in seriously ill patients awaiting lung transplantation, significant and clinically relevant improvements can be achieved by PR [3].

Comprehensive pulmonary rehabilitation (PR) treatment in the sub-acute phase of COVID-19 ensures continuity of care and results in good recovery in a short time and a reduction in the length of stay on acute wards [4]. PR has already been reported to be 
safe, feasible and effective [5]. A recent study demonstrates that improvements during PR were significantly higher for post-COVID-19 patients in comparison to patients with other lung diseases usually referred to PR [6], which was also shown for post-intensive-care unit patients suffering from COVID-19 [7]. This was not only true for the physical performance measured with Functional Independence Measurement (FIM) and 6 min walking distance (6-MWD), but also for the wellbeing of the patients, as indicated by the results of the Feeling Thermometer (FT).

It is already known that COVID-19 infection is not only a respiratory disease, as it can affect different body systems and functions, causing severe and complex disability, especially in more severe patients with prolonged hospitalization in ICUs or acute medical wards. The functional limitations of severe post-COVID-19 patients usually require an inpatient PR setting. Few publications suggest the provision of a comprehensive outpatient $\mathrm{PR}$ as an alternative setting for the anticipated respiratory impairments, e.g., muscle atrophy associated with physical deconditioning, as well as other negative consequences of COVID-19, including fatigue and hospital-induced anxiety or depression [8].

It is worthy of note that not all patients with pulmonary disease benefit from PR to the same degree. In COPD patients, the response rate was approximately two thirds $[9,10]$ and the non-responder rate in patients with interstitial lung diseases (ILD) was approximately $40 \%$. Both COPD and ILD patients with major limitations in the 6MWD at the beginning of the PR benefited the most from PR [10].

To date, there are no studies available on the response rates of post-COVID-19 patients to PR. Although there are some data showing the impressive benefits of a PR participation, the question of why some post-COVID-19 patients do not improve sufficiently despite participation remains unanswered. Therefore, we performed this study to identify patients who do not improve sufficiently and to find potential reasons for this.

\section{Materials and Methods}

\subsection{Participants and Procedures}

Patients overcoming the acute phase of COVID-19 infection were referred from acute hospitals for PR to the Zurich RehaCenter, Klinik Wald, Switzerland after hospitalization between March 2020 and May 2021. Post-COVID-19 patients were eligible for PR as soon as they were hemodynamically stable without the need of catecholamine or invasive ventilation and continuous monitoring. The data of these patients were prospectively analyzed according to performance and outcome during rehabilitation. We used the German version of the program RehaTIS ${ }^{\mathrm{TM}}$ by Softsolution, International AG, 15830 Lahti, Finland to record and control the individual rehabilitation process of each participant, including all therapies and procedures. The patient data and the results of the assessments were stored and taken for evaluation out of the clinic information system Phoenix ${ }^{\mathrm{TM}}$, CompuGroup Medical AG, 3007 Bern, Switzerland.

The patients were defined as responders if they achieved a walking distance (6-MWD) in the 6 Minute Walking Test (6-MWT) that corresponded to the reference walking distance by participating in the rehabilitation program [11]. The resulting gender-specific regression equations were used for men,

$$
6 \mathrm{MWD}=(7.57 \times \text { height } \mathrm{cm})-(5.02 \times \text { age })-(1.76 \times \text { weight } \mathrm{kg})-309 \mathrm{~m},
$$

and for women,

$$
6 \mathrm{MWD}=(2.11 \times \text { height } \mathrm{cm})-(2.29 \times \text { weight } \mathrm{kg})-(5.78 \times \text { age })+667 \mathrm{~m} .
$$

All the patients who evaluated provided written informed consent, and the local ethics committee approved the study protocol (BASEC-No 2020-01061). The data from patients who did not give their consent were not included in this analysis. This study was registered at the German Clinical Trials Register (DRKS00024613). 
The patients referred to PR were assessed with questionnaires, such as the Chronic Respiratory Disease Questionnaire (CRQ), the Hospital Anxiety and Depression Scale (HADS), the Cumulative Illness Rating scale (CIRS), and the Functional Independence Measure (FIM) within 2 days after admission for rehabilitation. In order to evaluate the response to PR, 6MWD, FIM, and Feeling Thermometer (FT) were performed at admission and before discharge. All the patients were deemed cognitively able to provide valid responses to the questionnaires by treating physicians. Comorbidities, pulmonary function testing (PFT), and laboratory values including blood gas analysis were assessed.

\subsection{Pulmonary Rehabilitation}

The usual duration of this inpatient PR program was 3 weeks and consisted primarily of an individualized endurance exercise and strength training. Contents were adapted to the patients functional performance and physical limitations. All over 25-30 therapy sessions on 5-6 weekdays were performed consisting of 4 exercise sessions per day. On Saturday, one exercise session was offered, while on Sunday no exercises were provided.

Details of the PR program have been described previously by our group $[5,6]$. In brief, exercise therapy included endurance training (cycling and treadmill), gymnastics (3 levels), in- and outdoor walking (3 levels), and strength training.

Partially bedridden patients started with in-bed cycling and MOTO-Med ${ }^{\circledR}$ (RECKTechnik GmbH \& Co. KG Medizintechnik, Reckstraße 1-5, D-88422 Betzenweiler, Germany). This was followed by initial walking attempts with walking aids until the first cycling interval training was possible. Walking training outside the clinic was offered at different levels, with level 1 at a slow pace with little incline and level 3 at a faster pace with frequent inclines. Gymnastics were offered at three levels of intensity. Gymnastics at level 1 took place mostly in a sitting position with several breaks between exercises; level 3 consisted of exercises in a standing position or walking with only very few or no breaks at all between exercises. The gymnastics consisted of a mixture of exercises to improve endurance, strength, coordination, range of motion, and balance.

Strength exercises were additionally performed 3-4 times per week individually according to recent American Thoracic Society/European Respiratory Society recommendations [1]. Exercise intensity was also symptom-controlled by Borg Scale (goal of Borg $4-5 / 10)[12,13]$.

Twice a week ( $1 \mathrm{~h}$ each), all the patients participated in educational sessions, including self-management, coping skills, self-medication, management of infections and exacerbations, dyspnea, use of oxygen, and nutrition interventions. If needed, the patients took part in a structured smoking cessation program, and received psychosocial support or diabetes advice.

\subsection{Exercise Capacity}

Exercise capacity was measured (6MWD) using the 6MWT, performed once a week, according to the guidelines of the American Thoracic Society and carried out by experienced, well-instructed examiners [14]. Regarding the relationship between the 6MWT distance and health outcomes, the inverse association with adverse outcomes was previously demonstrated in disease-specific populations such as those with heart failure, pulmonary disease, end-stage liver disease [15-18].

\subsection{Quality of Life}

As the standardized health-related quality of life (HRQoL) measurement tool, the German version of the Chronic Respiratory Disease Questionnaire (CRQ) was used. The 20 items represent areas of dysfunction that are most significant to patients with chronic respiratory diseases. The patients completed the CRQ independently. Four aspects of HRQoL were evaluated: dyspnea, fatigue, emotional function, and mastery. Each domain included 4 to 7 items, graded on a 7 point Likert scale. The item scores within a domain were summated to provide a total score for each domain. While a higher score indicated a 
better HRQoL, the minimally important difference was reflected by a change in score of 0.5 on a 7 point scale. In previous research, the CRQ was used to evaluate the effects of treatment in clinical trials as well as in clinical practice. Evidence has generally shown that the CRQ is a reliable and reproducible tool [19].

\subsection{Functional Independence Measure (FIM)}

The FIM is an 18 item measurement tool that explores the severity of an individual's physical and psychological disability, especially in rehabilitation patients [20]. The tool is also used to assess changes in patients' functional status in response to rehabilitation or medical intervention. The FIM uses the level of assistance for individual needs to grade functional status from total independence to total assistance. As the severity of disability changes during rehabilitation, the data generated by the FIM Instrument can be used to track such changes and analyze the outcomes of rehabilitation. FIM change scores associated with MID were 22 for the total FIM, 17 for motor FIM, and 3 for cognitive FIM, respectively [21].

\subsection{Hospital Anxiety and Depression Scale (HADS)}

The HADS was originally designed as a short, easy-to-use screening tool for depression and anxiety in patient status in response to rehabilitation. This questionnaire is focused on non-physical symptoms and can be used to diagnose depression in people with significant physical limitations. It comprises seven questions for anxiety and seven questions for depression, and takes 2-5 min to complete. Both scales ranging from 0 to 21 with higher scores indicate more severe distress. Cut-off scores are available for quantification, e.g., a score of 8 or more for anxiety has a specificity of 0.78 and a sensitivity of 0.9 , and for depression a specificity of 0.79 and a sensitivity of 0.83 [22].

\subsection{Cumulative Illness Rating Scale (CIRS)}

The CIRS is a comprehensive method for recording diseases in 14 organ systems on the basis of an evaluation of 0 to 4 points, with the help of which a cumulative score is calculated. The range of the score is $0-56$ points. When evaluating the CIRS, each individual illness in the corresponding organ system must be classified. If there were different diseases within the same organ system, only the disease that was most pronounced was evaluated. The CIRS was used as a morbidity index in order to assess a patient's level of disability and as an indicator of health status, including predicted 18 month mortality and social function [23]. The calculated CIRS at admission is useful for predicting important hospital outcomes such as high risk of death or long stays and to better anticipate end-of-life issues.

\subsection{Feeling Thermometer (FT)}

We used the FT to determine and compare the patients' feelings about their wellbeing by applying a numeric rating of their feelings toward an imaginary scale in terms of degrees, with their attitudes corresponding to temperatures. The minimal important difference was defined between 5 and 8 degrees [24].

\subsection{Pulmonary Function Tests (PFT) and Blood Gas Analysis}

Spirometry and Body-Plethysmography (Master Screen Body; Jaeger GmbH, Hoechberg, Germany) were performed once on PR admission, in accordance with recent guidelines $[25,26]$. Arterial blood gases were taken at rest under room air conditions (Radiometer ABL800, Willich, Germany) on admission to PR [27]. Blood count, creatinine, and Creactive protein (CRP) were obtained from the external laboratory Medica, Medizinische Laboratorien Dr. F. Kaeppeli AG, Zurich, Switzerland.

\subsection{Statistics}

The continuous variables were represented as mean with standard deviation (SD), and the discrete variables with absolute and relative numbers. The correlations between 
the continuous variables for pairwise complete observations were calculated using Pearson correlation coefficient. Univariate comparisons between patients who reached the target range and patients who did not reach the target range were performed using t-tests or chi square tests. Logistic regression models and classification and regression trees (CART) were used for multivariate analysis. CART analyses help to divide patients into different groups according to influencing variables. In our case, the division was made into patients who were likely to reach the reference walking distance, those who would not reach the reference walking distance, and groups in between. All the variables with a $p$ value $<0.1$ and a rate of missing values $<25 \%$ were selected for multivariate analysis. To avoid multicollinearity variables, variance inflation factors were calculated (VIF). If two variables had a VIF $>4$, one variable was selected for modelling. R (Version 4.1.0, Microsoft R Open, Microsoft Corporation, One Microsoft Way, Redmond, WA 98052-6399, USA) was used for all the analyses. A significance level of $5 \%$ was set.

\section{Results}

Between January 2020 and May 2021, a total of 244 post-COVID-19 patients were referred to PR. In total, 61 patients were excluded from the analysis due to several reasons ( $n=27$ did not give informed consent; $n=6$ withdraw their consent; $n=12$ early discharge from PR; $n=16$ lack of collected data). The remaining 183 patients were evaluated in the study. None of the participants reached the reference walking distance on admission to PR. According to the results of the 6MWT, in the pre-post comparison of all the post-COVID-19 patients, 94 out of 183 patients reached the referencing walking distance at discharge. Those patients were defined as "responders", whereas the 89 patients did not reach the referenced walking distance, defined as "non-responders". The chart review process is depicted in Figure 1.

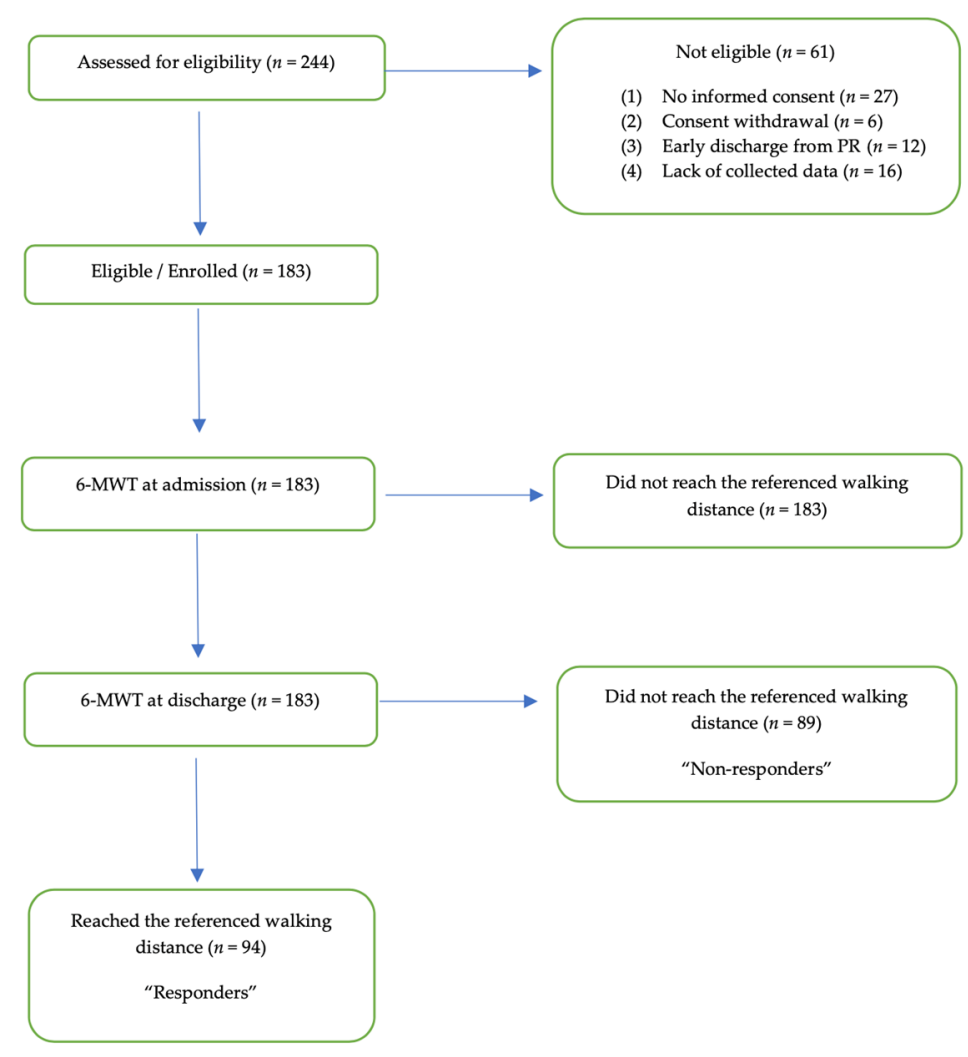

Figure 1. Study design. 


\subsection{Baseline Characteristics}

The overall collective had a mean age of 69 years on average. A total of $32.6 \%$ of the patients were female $(n=60)$. According to age and sex, there were no significant differences between responders and non-responders. Acute Hospital stay was 23.5 days on average, with 9.2 days on ICU and 5.7 days on ventilation (Table 1). Oxygen supply at discharge from the acute hospital was needed in $85 \%$ of the patients. According to the World Health Organization (WHO) criteria $55 \%$ of the patients suffered from a severe disease (with severe pneumonia) that required oxygen therapy and $45 \%$ developed a critical disease with complications, such as respiratory failure, acute respiratory distress syndrome, thromboembolism, sepsis, and/or multiorgan failure [28]. Almost half of the patients $(n=88)$ had an initial 6MWT distance $<200 \mathrm{~m}$, which required an individual adaptation of training.

Table 1. Baseline Characteristics of Responders and Non-Responders.

\begin{tabular}{|c|c|c|c|c|}
\hline & Overall & Responder & Non-Responder & $p$-Value \\
\hline$n$ & 183 & 94 & 89 & \\
\hline Age years (mean (SD)) & $68.99(10.21)$ & $69.62(10.09)$ & $68.45(10.34)$ & 0.441 \\
\hline BMI kg/m² (mean (SD)) & $27.25(5.5)$ & $27.38(4.5)$ & $27.11(6.4)$ & 0.746 \\
\hline Sex, female (\%) & $60(33)$ & $27(29)$ & $32(36)$ & 0.375 \\
\hline ICU-days (mean (SD)) & $9.23(11.8)$ & $7.98(10.6)$ & $10.65(12.9)$ & 0.129 \\
\hline Ventilation days (mean (SD)) & $5.65(9.5)$ & $4.65(8.0)$ & $6.78(10.9)$ & 0.132 \\
\hline Hospital days (mean (SD)) & $23.50(13.5)$ & $21.46(11.0)$ & $25.81(15.4)$ & 0.29 \\
\hline Rehabilitation days (mean (SD)) & $21.58(8.7)$ & $21.39(8.4)$ & $21.80(9.1)$ & 0.755 \\
\hline Therapy minutes/week & $1658(1268)$ & $1752(1393)$ & $1563(1125)$ & 0.316 \\
\hline 6-MWD admission \% reference value (SD) & $53.11(38.02)$ & $73.06(35.96)$ & $32.04(27.36)$ & $<0.001$ \\
\hline 6-MWD admission meters (mean (SD)) & $187(134)$ & $250(126)$ & $119(104)$ & $<0.001$ \\
\hline \multicolumn{5}{|c|}{ Comorbidities } \\
\hline non-smoker (\%) & $132(71.7)$ & $73(77.7)$ & $58(65.2)$ & 0.88 \\
\hline $\operatorname{COPD} n(\%)$ & $10(5.5)$ & $3(3.2)$ & $10(11.2)$ & 0.3 \\
\hline No COPD & 173 & 91 & 79 & \\
\hline COPD stage I & $1(0.6)$ & $0(0.0)$ & $1(1.2)$ & \\
\hline COPD stage II & $3(1.7)$ & $1(1.1)$ & $2(2.3)$ & \\
\hline COPD stage III & $4(2.2)$ & $1(1.1)$ & $3(3.5)$ & \\
\hline COPD stage IV & $2(1.1)$ & $1(1.1)$ & $1(1.2)$ & \\
\hline Alcohol abuse $n(\%)$ & $13(7.1)$ & $6(6.4)$ & $7(7.9)$ & 0.919 \\
\hline Coronary Artery Disease $n(\%)$ & $32(17.4)$ & $11(11.7)$ & $21(23.6)$ & 0.55 \\
\hline Diabetes $n(\%)$ & $51(27.7)$ & $22(23.4)$ & $29(32.6)$ & 0.223 \\
\hline Peripheral Arterial Disease $n(\%)$ & $12(6.5)$ & $4(4.3)$ & $8(9.0)$ & 0.320 \\
\hline Atrial Fibrillation $n(\%)$ & $18(9.8)$ & $5(5.3)$ & $13(14.6)$ & 0.63 \\
\hline Stroke $n(\%)$ & $8(4.3)$ & $3(3.2)$ & $5(5.6)$ & 0.659 \\
\hline $\operatorname{VTE} n(\%)$ & $4(2.2)$ & $1(0.0)$ & $3(3.2)$ & 0.453 \\
\hline Dyslipidaemia $n(\%)$ & $34(18.5)$ & $15(16.0)$ & $19(21.3)$ & 0.455 \\
\hline Arterial hypertension $n(\%)$ & $99(53.8)$ & $47(50.0)$ & $51(57.3)$ & 0.400 \\
\hline Pulmonary hypertension $n(\%)$ & $2(1.1)$ & $1(1.1)$ & $1(1.1)$ & 1.000 \\
\hline Psychiatric disease $n(\%)$ & $17(9.2)$ & $9(9.6)$ & $8(9.0)$ & 1.000 \\
\hline
\end{tabular}


Table 1. Cont.

\begin{tabular}{|c|c|c|c|c|}
\hline & Overall & Responder & Non-Responder & $p$-Value \\
\hline$n$ & 183 & 94 & 89 & \\
\hline Renal failure $n(\%)$ & $31(16.9)$ & $12(12.8)$ & 19 (21.6) & 0.166 \\
\hline CIRS pts (mean (SD)) & $12.74(5.54)$ & $11.76(5.02)$ & $13.80(5.91)$ & 0.13 \\
\hline \multicolumn{5}{|c|}{ Assessments } \\
\hline HADS A (mean (SD)) & $5.28(3.62)$ & $4.62(3.07)$ & $5.91(3.99)$ & 0.30 \\
\hline HADS D (mean (SD)) & $5.52(3.24)$ & $5.16(3.00)$ & $5.88(3.47)$ & 0.178 \\
\hline CRQ (mean (SD)) & $4.71(1.03)$ & $4.70(1.10)$ & $4.71(0.97)$ & 0.929 \\
\hline FIM total (mean (SD)) & $98.12(15.75)$ & $103.16(12.33)$ & $92.93(17.30)$ & $<0.001$ \\
\hline FIM socio (mean (SD)) & $29.70(5.87)$ & $30.63(6.44)$ & $28.73(5.09)$ & 0.29 \\
\hline FIM motoric (mean (SD)) & $68.68(12.89)$ & $73.04(11.05)$ & $64.20(13.20)$ & $<0.001$ \\
\hline FT (mean (SD)) & $53.79(16.99)$ & $52.96(17.05)$ & $54.91(16.87)$ & 0.468 \\
\hline
\end{tabular}

Notes: ICU, Intensive Care Unit; 6MWD, Six-minute walking distance; CIRS, Cumulative Illness Rating Scale; HADS A, Hospital Anxiety and Depression Scale anxiety; HADS D, Hospital Anxiety and Depression scale depression; FIM, functional independence measurement; $\mathrm{CRQ}$, chronic Respiratory questionnaire; VTE, venous thromboembolism; FT, feeling thermometer; COPD, chronic obstructive pulmonary disease (staging according GOLD guidelines).

\subsection{Comorbidities}

The CIRS in the overall collective was 12.7 points, on average. A relevant number of patients had cardiovascular risk factors, such as arterial hypertension (54\%), smoking (29\%), diabetes $(28 \%)$ or established coronary artery disease (17\%). Mean BMI was $27 \mathrm{~kg} / \mathrm{m}^{2}$ (Table 1),

\subsection{Assessments on Admission}

The mean duration of the pulmonary rehabilitation program was 21.6 days, with 1658 therapy minutes per week on average. The responders had a significantly higher total and motoric FIM score at admission than the non-responders (103.2 and 73.0 in responders vs. 92.9 and 64.2 in non-responders; $p<0.001$ for both). No significant differences were found for HADS, CRQ, Feeling Thermometer, and laboratory parameters (Tables 1 and 2). Out of 156 correctly answered HADS questionnaires a HADS-D score $\geq 10$ points was found in 19 patients (12\%) and a HADS-A score $\geq 10$ points was also found in 19 patients $(12 \%)$, with no significant difference in the distribution for both groups.

\section{- Pulmonary function tests on admission}

The FEV1\% predicted at admission was significantly higher in the responders than in the non-responders $(83.2 \%$ vs. $63.1 \% ; p<0.001)$. The same applied to the FVC $\%$ predicted $(80 \%$ in responders vs. $62 \%$ in non-responders; $p<0.001)$. The responders demonstrated a higher diffusion capacity on admission compared to the non-responders (DLCO\% predicted $62 \%$ in responders vs. $47 \%$ in non-responders) (Table 2 ).

- Functional and subjective changes during PR

Improvements for each group during PR are shown in Table 3. Only $\triangle 6-\mathrm{MWD}$ (distance in meters walked on the 6 min walking test at discharge minus distance walked on admission) was different between the responders and the non-responders $(175.80 \mathrm{~m}$ (109.13) vs. $131.65 \mathrm{~m}$ (87.49)). Regarding the groups according to reaching the MCID of the $6 \mathrm{MWD}$, we found no significant differences (Table 3). Changes in 6MWD, total and motoric FIM and FT during PR were significant for the whole cohort, for both responders and non-responders (Table 4). Changes in 6MWD, total FIM, and FT during PR were significant. 
Table 2. Pulmonary function testing (PFT) and Laboratory Parameters of Responders and Non-Responders.

\begin{tabular}{|c|c|c|c|c|}
\hline & Overall & Responder & Non-Responder & $p$-Value \\
\hline \multicolumn{5}{|c|}{ Pulmonary function testing (PFT) } \\
\hline FEV1\% pred. (mean (SD)) & $74.28(21.59)$ & $83.16(19.43)$ & $63.07(18.91)$ & $<0.001$ \\
\hline FVC\% pred. (mean (SD)) & $71.88(20.76)$ & $80.03(18.60)$ & $61.59(18.79)$ & $<0.001$ \\
\hline FEV1\% FVC (mean (SD)) & $80.28(10.74)$ & $80.53(9.24)$ & $79.97(12.45)$ & 0.760 \\
\hline DLCO\% pred. (mean (SD)) & $56.35(17.81)$ & $62.33(17.94)$ & $46.95(13.02)$ & $<0.001$ \\
\hline \multicolumn{5}{|c|}{ Laboratory Parameters } \\
\hline $\mathrm{PaO} 2 \mathrm{kPa}($ mean (SD)) & $9.55(6.50)$ & $9.15(1.81)$ & $9.97(9.14)$ & 0.433 \\
\hline $\mathrm{PaCO} 2 \mathrm{kPa}($ mean $(\mathrm{SD}))$ & $4.53(0.77)$ & $4.47(0.72)$ & $4.58(0.81)$ & 0.405 \\
\hline $\mathrm{SpO} 2 \%$ (mean (SD)) & $93.46(2.94)$ & $93.55(2.80)$ & $93.36(3.11)$ & 0.658 \\
\hline Procalcitonin ng/mL (mean (SD)) & $1.44(4.31)$ & $0.59(0.74)$ & $2.46(6.23)$ & 0.25 \\
\hline CRP mg/dL (mean (SD)) & $139.87(109.79)$ & $131.78(97.72)$ & $149.12(121.76)$ & 0.292 \\
\hline Creatinine mg/L (mean (SD)) & $118.08(109.49)$ & $107.92(78.66)$ & $129.55(134.53)$ & 0.183 \\
\hline Ferritin mg/L (mean (SD)) & $1536.85(1552.31)$ & $1513.36(1644.27)$ & $1570.07(1431.46)$ & 0.859 \\
\hline Hemoglobin g/L (mean (SD)) & $104.47(23.25)$ & $107.46(23.88)$ & $101.10(22.27)$ & 0.65 \\
\hline Leukocytes $\times 10^{9} /$ L (mean (SD)) & $12.31(6.06)$ & $11.53(5.69)$ & $13.20(6.34)$ & 0.62 \\
\hline Thrombocytes $\times 10^{9} / \mathrm{L}($ mean (SD)) & $211.35(94.09)$ & $205.67(93.40)$ & $213.66(89.01)$ & 0.555 \\
\hline CPK U/L (mean (SD)) & $415.84(742.37)$ & $435.63(762.69)$ & $392.38(725.81)$ & 0.780 \\
\hline D-dimer $\mu / L$ (mean (SD)) & $5.98(13.08)$ & $4.67(8.28)$ & 7.54 (17.09) & 0.241 \\
\hline Sodium mEq/L (mean (SD)) & $136.67(4.65)$ & $136.53(4.76)$ & $136.79(4.57)$ & 0.713 \\
\hline Potassium mEq/L (mean (SD)) & $4.12(0.52)$ & $4.02(0.50)$ & $4.23(0.51)$ & 0.6 \\
\hline Protein g/dL (mean (SD)) & $70.74(47.25)$ & $74.71(46.68)$ & $65.97(49.12)$ & 0.605 \\
\hline
\end{tabular}

Notes: CPK, creatien phosphokinase; CRP, C-reactive protein; SpO2, oxygen saturation; DLCO, lung diffusion capacity.FEV1, forced expiratory volume in one second; FVC, forced vital capacity; DLCO, lung diffusion capacity.

Table 3. PR Results according to 6-MWD, FT and FIM of responders and non-responders.

\begin{tabular}{|c|c|c|c|c|}
\hline & Overall & Responder & Non-Responder & $p$-Value \\
\hline$n$ & 183 & 94 & 89 & \\
\hline $6 \mathrm{MWD}$ at discharge $\%$ reference value (SD) & $98.55(37.78)$ & $126.87(22.54)$ & $68.63(25.56)$ & $<0.001$ \\
\hline$\triangle 6 \mathrm{MWD}$ meter (mean (SD)) & $154.20(101.11)$ & $175.80(109.13)$ & $131.65(87.49)$ & 0.003 \\
\hline $\begin{array}{c}\Delta 6-\mathrm{MWD} \text { meter }>54 \mathrm{~m} \text { (minimal important } \\
\text { difference) } n(\%)\end{array}$ & $156(84.8)$ & $81(86.2)$ & $74(83.1)$ & 0.717 \\
\hline$\Delta \mathrm{FIM}$ tot (mean $(\mathrm{SD}))$ & $15.36(13.99)$ & $14.85(14.69)$ & $15.76(13.24)$ & 0.666 \\
\hline$\Delta$ FIM motoric (mean (SD)) & $12.27(10.79)$ & $10.68(9.99)$ & $13.86(11.40)$ & 0.048 \\
\hline$\Delta \mathrm{FT}($ mean $(\mathrm{SD}))$ & $21.12(14.46)$ & $22.53(15.32)$ & $19.67(13.41)$ & 0.242 \\
\hline
\end{tabular}

Notes: 6MWD, six-minute walking distance; FIM, Functional Independence Measurement; FT, feeling thermometer; pts, points.

Regression models were run once with and once without the PFT parameters, since PFT was performed in only $75 \%$ of the patients on admission. In both models, 6-MWD on admission (OR: 0.99 (0.99-1.00) p<0.001; OR: $0.99(0.99-1.00), p=0.002)$ and motor FIM (OR: 0.96 (0.93-0.99), $p=0.002$; OR: $0.93(0.88-0.97), p=0.004)$ were significant. In the model with pulmonary function parameters, FVC was also significant (OR: 0.95 (0.93-0.97) $p<0.001$ ) (Table 5). 
Table 4. Pre-post comparison between responders and non-responders according to 6MWD, FIM tot, FIM motoric, and FT.

\begin{tabular}{|c|c|c|c|c|c|c|c|c|c|}
\hline \multirow{3}{*}{$n$} & \multicolumn{3}{|c|}{ Overall } & \multicolumn{3}{|c|}{ Responder } & \multicolumn{3}{|c|}{ Non-Responder } \\
\hline & \multicolumn{3}{|c|}{183} & \multicolumn{3}{|c|}{94} & \multicolumn{3}{|c|}{89} \\
\hline & Pre & Post & $p$ & Pre & Post & $p$ & Pre & Post & $p$ \\
\hline 6-MWD meter (mean (SD)) & $\begin{array}{c}187.25 \\
(133.77)\end{array}$ & $\begin{array}{c}341.42 \\
(131.80)\end{array}$ & $<0.001$ & $\begin{array}{c}250.35 \\
(126.45)\end{array}$ & $\begin{array}{l}426.10 \\
(83.40)\end{array}$ & $<0.001$ & $\begin{array}{c}118.55 \\
(104.45)\end{array}$ & $\begin{array}{l}250.20 \\
(111.41)\end{array}$ & $<0.001$ \\
\hline FIM tot. (mean (SD)) & $\begin{array}{c}98.12 \\
(15.75)\end{array}$ & $\begin{array}{l}113.51 \\
(12.94)\end{array}$ & $<0.001$ & $\begin{array}{l}103.16 \\
(12.33)\end{array}$ & $\begin{array}{l}117.11 \\
(8.30)\end{array}$ & $<0.001$ & $\begin{array}{c}92.93 \\
(17.30)\end{array}$ & $\begin{array}{c}109.51 \\
(15.81)\end{array}$ & $<0.001$ \\
\hline FIM motoric (mean (SD)) & $\begin{array}{c}68.68 \\
(12.89)\end{array}$ & $\begin{array}{c}81.22 \\
(10.75)\end{array}$ & $<0.001$ & $\begin{array}{c}73.04 \\
(11.05)\end{array}$ & $\begin{array}{l}83.72 \\
(8.78)\end{array}$ & $<0.001$ & $\begin{array}{c}64.20 \\
(13.20)\end{array}$ & $\begin{array}{c}78.41 \\
(12.08)\end{array}$ & $<0.001$ \\
\hline FT degrees (mean (SD)) & $\begin{array}{c}53.79 \\
(16.99)\end{array}$ & $\begin{array}{c}75.18 \\
(13.14)\end{array}$ & $<0.001$ & $\begin{array}{c}52.96 \\
(17.05)\end{array}$ & $\begin{array}{c}75.24 \\
(13.52)\end{array}$ & $<0.001$ & $\begin{array}{c}54.91 \\
(16.87)\end{array}$ & $\begin{array}{c}75.62 \\
(12.18)\end{array}$ & $<0.001$ \\
\hline
\end{tabular}

Notes: 6MWD, six-minute walking distance; FIM, Functional Independence Measurement; FT, feeling thermometer.

Table 5. Correlations models excluding and including Forced Vital Capacity.

\begin{tabular}{|c|c|c|c|c|}
\hline & \multicolumn{2}{|c|}{ Model without FVC $(n=181)$} & \multicolumn{2}{|c|}{ Model with FVC $(n=136)$} \\
\hline & Odds Ratios [95\% CI] & $p$ & Odds Ratios $[95 \% \mathrm{CI}]$ & $p$ \\
\hline ICU days & $0.98[0.92-1.04]$ & 0.564 & $0.98[0.91-1.06]$ & 0.638 \\
\hline Hospital days & $1.02[0.96-1.07]$ & 0.587 & $1.00[0.93-1.07]$ & 0.977 \\
\hline 6MWD admission (per meter) & $0.99[0.99-1.00]$ & $<0.001$ & $0.99[0.99-1.00]$ & 0.002 \\
\hline Smoker (non-smoker) & $0.57[0.25-1.32]$ & 0.193 & $0.64[0.22-1.83]$ & 0.403 \\
\hline CAD & $1.50[0.57-4.05]$ & 0.415 & $2.39[0.72-8.55]$ & 0.163 \\
\hline Arterial fibrillation & $2.76[0.74-11.44]$ & 0.140 & $3.85[0.73-23.18]$ & 0.121 \\
\hline FIM motoric (per each point) & $0.96[0.93-0.99]$ & 0.020 & $0.93[0.88-0.97]$ & 0.004 \\
\hline Hemoglobin & 1.01 [0.99-1.03] & 0.474 & $1.01[0.98-1.03]$ & 0.633 \\
\hline Leukocytes & $1.06[0.99-1.13]$ & 0.084 & $1.03[0.93-1.13]$ & 0.549 \\
\hline Potassium & $1.57[0.79-3.27]$ & 0.206 & $1.32[0.49-3.66]$ & 0.578 \\
\hline FVC $\%$ pred & & & $0.95[0.93-0.97]$ & $<0.001$ \\
\hline
\end{tabular}

Notes: ICU, Intensive Care Unit; 6MWD, six-minute walking distance; CAD, coronary artery disease; CIRS, Cumulative Illness Rating Scale; FIM, Functional Independence Measurement; FVC, forced vital capacity.

The most important variable in the tree model was $6 \mathrm{MWD}$ on admission. Here, the split was set at $130 \mathrm{~m}$. The patients with a $6 \mathrm{MWD}>130 \mathrm{~m}$ on admission and $>83 \%$ of the reference FVC value were the most likely to reach the predicted walking distance (Figure 2). 


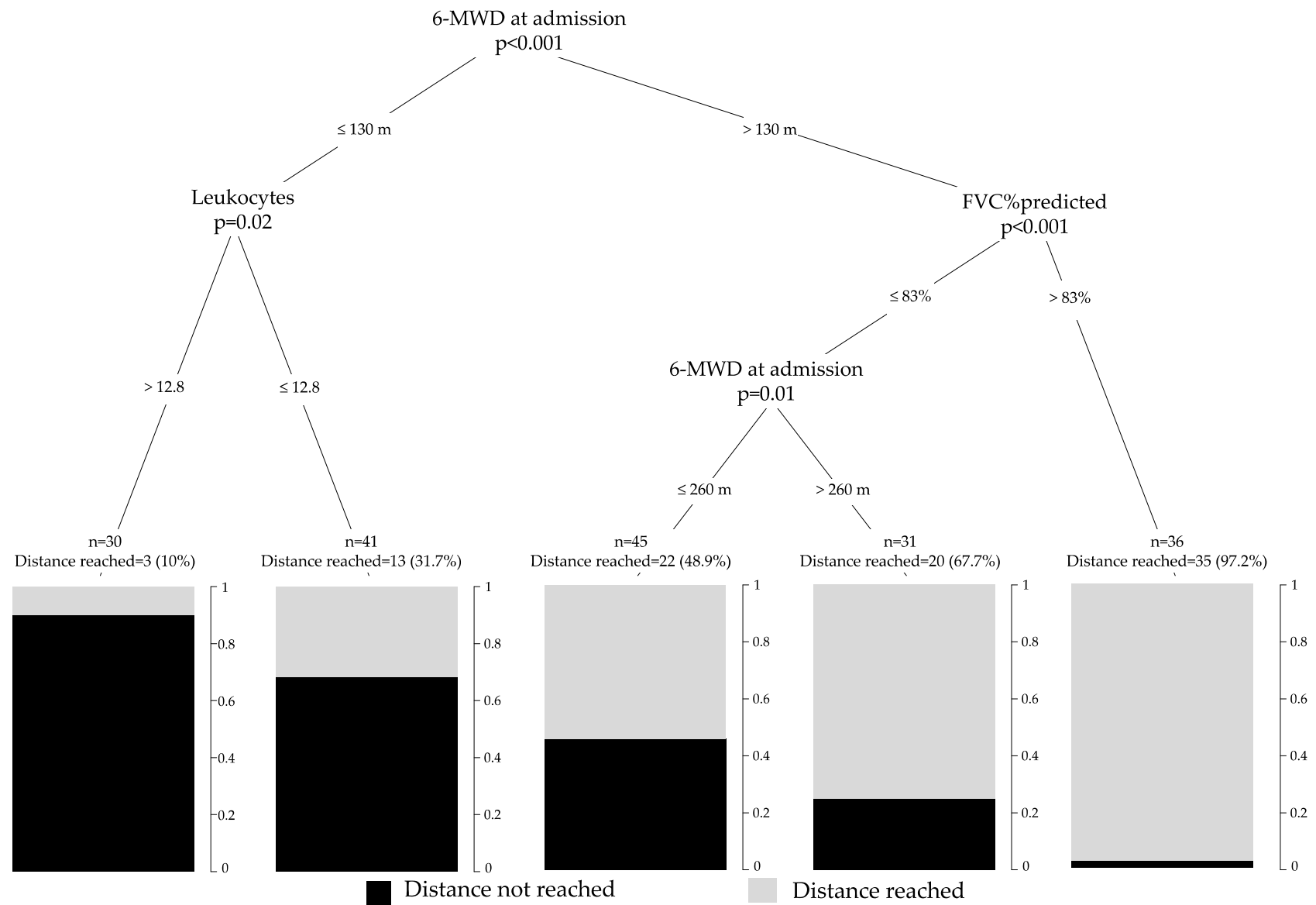

Figure 2. Separation of non-responders into different groups according to influencing variables (tree model). Notes: 6MWD, six-minute walking distance; FVC, forced vital capacity.

\section{Discussion}

Our study demonstrated that patients with severe COVID-19 benefit from rehabilitation to varying degrees. Indeed, patients with lower 6MWD and lower motoric FIM scores on admission combined with a restrictive ventilatory disorder were at increased risk of failing to reach the age- and gender-related target values for 6MWD during a comprehensive PR program.

Interestingly, we did not observe any differences in the baseline characteristics, except for FIM scores and pulmonary function testing parameters. These findings are confirmed by the recent study of Maniscalco et al., which suggested that multidisciplinary rehabilitation may be useful in post-COVID-19 patients regardless of the presence of preexisting cardiorespiratory comorbidities [29]. Several studies emphasize that the presence of comorbidities, complications from an intensive care treatment, and virus-associated pulmonary, cardiac, hematological and neurological damage, challenge the concept of PR [30-32]. However, in our study, we did not observe any difference in comorbidities, length of intensive care treatment or laboratory parameters, nor in the intensity of PR, as measured by therapy minutes per week between responders and non-responders.

It is recommended to pay attention to the improvements in 6MWD during PR, which provides an assessment of exercise capacity and can better reflect daily activity than laboratory tests [33]. The $54 \mathrm{~m}$ threshold for 6MWD is considered representative of a clinically significant change for patients with chronic respiratory diseases [34]. The majority of our patients $(83 \%)$ largely exceeded this value at the end of PR, although it has been highlighted that a statistically significant mean increase in $6 \mathrm{MWD}$ in a group of study participants is often much less than a clinically significant increase in an individual patient [35]. The fact that a large number of patients who were very limited in their ability to walk upon arrival in our 
facility were able to reach their individual reference walking distance at the end of the PR program, even in the presence of several comorbidities, reinforces our view that all patients hospitalized for COVID-19 should undergo a multidisciplinary rehabilitation program.

Studies have shown that, usually, the patients with the greatest limitations benefit most from PR [36]. In our study, the patients with the greatest limitations as assessed by 6MWD and FIM were also the patients who did not reach the goal of achieving the set level in walking distance, which is in contrast to the expected results for patients with pulmonary diseases referred to PR so far. We assume that the systemic limitations caused by COVID-19 infection are so pronounced in numerous patients that even a three-week PR with conventional contents is currently not enough to convert patients back to normal. This assumption is supported by the results of Skjorten et al., who recently showed that significant cardiovascular-pulmonary limitations were still detectable while performing ergo-spirometry in $1 / 3$ of the post-COVID patients after 3 months [37]. Additionally, Tudoran C. and Tudoran M. et al. detected alterations in the left ventricular systolic and diastolic function in patients with post-acute COVID-19 syndrome by transthoracic echocardiography, which may also serve as an explanation for the reduction in exercise capacity [38,39].

DLCO \%-predicted is supposed to be the strongest independent factor associated with previous severe/critical COVID-19. Compared with non-severe cases, severe patients exhibited a higher incidence of DLCO impairment and experienced greater TLC decrease and 6MWD decline [38]. Our study showed that 6MWD and FVC\% predicted were the most important variable to reach the predicted walking distance. In this context, it has been suggested that the severity of pulmonary inflammation may be the reason for impaired PFT in COVID-19 patients [39]. Since there is evidence that exercise training represents a strategy to elicit an anti-inflammation effect, which may help to decrease the risk or progression of several disorders of an inflammatory nature [40], as are the parenchymal and vascular sequelae of COVID-19, we wonder why this subgroup did not benefit the most. One could speculate that the effect should be different because of the systemic inflammation that characterizes the cardiorespiratory diseases [41].

As reported previously, the increase in walking distance in post-COVID-19 patients is significantly higher than in patients who are usually admitted to PR [11,35,42]. At least according to the present results, the cohort of post-COVID patients differed significantly from the patients with lung diseases usually admitted to PR. The limitations in physical capacity according to the results of the initial 6MWD of the post-COVID-19 patients exceed the limitations observed in patients usually participating in PR [6]. Although all the patients benefit from PR on average, we identified a subgroup that benefited less. In our view, it is of particular interest to identify these patients with a high likelihood of lower response in terms of walking distance enhancement early in the onset of PR to pay special attention to these patients. Our tree model analysis might further help to identify these patients at risk. Indeed, a first split was set with a $6 \mathrm{MWD}$ at $130 \mathrm{~m}$. Patients with a $6 \mathrm{MWD} \leq 130 \mathrm{~m}$ and higher leucocytes count $\left(>12.8 \times 10^{9} / \mathrm{L}\right)$ demonstrated a high probability of not reaching the individual predicted walking distance, while patients with a $6 \mathrm{MWD}>130 \mathrm{~m}$ and an FVC $>83 \%$ were most likely to reach the individual predicted walking distance.

The current recommendations of the professional societies for the rehabilitation of post-COVID patients are very similar to the usual recommendations for PR in pulmonary patients. Currently, COVID-19 survivors with pre-existing/ongoing lung function impairment at 6-8 weeks following hospital discharge should receive a comprehensive pulmonary rehabilitation program consistent with established international standards, compared to no pulmonary rehabilitation program [29]. An adaptation of the rehabilitation contents for more limited patients is not planned at present. However, these recommendations only meet the needs of some post-COVID patients. Therefore, further studies should clarify a variation of PR contents or intensify care for post-COVID patients with greater functional limitations. In this context, Carda et al. suggested the provision of PR treatment based on 
the content that is usually recommended in lung fibrosis, since COVID-19 can also induce a restrictive lung disease [43].

According to the results of our analysis, patients benefit from participation in this PR program not only for the objective parameters according to the performance tests, but also subjectively, according to the results of the feeling thermometer. However, according to our analysis, the credo of "one size fits all" is not applicable to the PR of post-COVID patients. Further studies are needed to develop an individualized PR program, especially in post-COVID patients, to meet individual needs.

\section{Limitations}

This study featured limitations. First, this study represents a cohort of severe postCOVID-19 patients referred to a single rehabilitation center. Therefore, the results could not be transferred to all post-COVID 19 patients or to all PR centers. Second, the results of $24 \%$ of the patients admitted to our facilities could not be analyzed, even though a prospective study design was chosen. A more complete coverage of all the patients would have been desirable, but this was not achievable. Third, the study included patients from the first and second wave of the pandemic. At that time, the proportion of patients with comorbidities and older patients predominated. In the current, fourth wave, the composition of patients has changed towards younger and unvaccinated patients, as well as patients with poorer immune response to vaccination. To what extent our results also apply to the typical patients of the fourth wave cannot be estimated. Fourth, the simple consideration of the walking distance from admission to rehabilitation showed limitations. The patients in the non-responder group started PR with $6 \mathrm{MWD}$ at $32 \%$ of the reference value and were less likely to reach the reference value compared to the responder group starting PR with $6 \mathrm{MWD}$ at $73 \%$ of reference value. Therefore, the determination of the walking distance alone should not be overinterpreted. However, by adding the PFT values to the results of the initial 6MWD, the predictive value for reaching the reference value increased to $97.2 \%$.

\section{Conclusions}

This study identified a subgroup of COVID-19 patients with lower 6MWD, lower motoric FIM scores, and lower FVC at admission as being at a high risk of not reaching their target values for physical performance, despite intensive inpatient rehabilitation. The identification of these patients allows us to develop optimized concepts within PR for these patients.

Author Contributions: Conceptualization, M.S., M.M.B. and M.H.; methodology, M.S. and M.H.; software, M.S.; validation, M.S., S.S. and M.H.; formal analysis, M.H., S.S. and M.S.; investigation, A.M.P.-E., M.H. and M.S.; resources S.S. and M.C.; data curation, S.S.; writing-original draft preparation, M.S., M.M.B., M.H. and W.W.; writing-review and editing, M.S., M.M.B., M.H., S.S., W.W. and A.M.P.-E. All authors have read and agreed to the published version of the manuscript.

Funding: This research received no external funding.

Institutional Review Board Statement: The study was conducted according to the guidelines of the Declaration of Helsinki and approved by the Ethics Committee Swissethics; BASEC-No 2020-01061 (15 August 2020).

Informed Consent Statement: Informed consent was obtained from all subjects involved in the study.

Data Availability Statement: Data supporting the reported results can be provided upon reasonable request by the corresponding author.

Acknowledgments: We would like to thank Bernhard Ulm, unabhängige statistische Beratung Bernhard Ulm, Kochelseestr 11, D-81371 Munich.

Conflicts of Interest: The authors declare no conflict of interest. 


\section{References}

1. Spruit, M.A.; Singh, S.J.; Garvey, C.; ZuWallack, R.; Nici, L.; Rochester, C.; Hill, K.; Holland, A.E.; Lareau, S.C.; Man, W.D.-C.; et al. An Official American Thoracic Society/European Respiratory Society Statement: Key Concepts and Advances in Pulmonary Rehabilitation. Am. J. Respir. Crit. Care Med. 2014, 189, 1570. [CrossRef]

2. McCarthy, B.; Casey, D.; Devane, D.; Murphy, K.; Murphy, E.; Lacasse, Y. Pulmonary rehabilitation for chronic obstructive pulmonary disease. Cochrane Database Syst. Rev. 2015, 2, CD003793. [CrossRef]

3. Kenn, K.; Gloeckl, R.; Soennichsen, A.; Sczepanski, B.; Winterkamp, S.; Boensch, M.; Welte, T. Predictors of Success for Pulmonary Rehabilitation in Patients Awaiting Lung Transplantation. Transplantation 2015, 99, 1072-1077. [CrossRef]

4. Bertolucci, F.; Sagliocco, L.; Tolaini, M.; Posteraro, F. Comprehensive rehabilitation treatment for sub-acute COVID-19 patients: An observational study. Eur. J. Phys. Rehabil. Med. 2021, 57, 208-215. [CrossRef]

5. Hermann, M.; Pekacka-Egli, A.M.; Witassek, F.; Baumgaertner, R.; Schoendorf, S.; Spielmanns, M. Feasibility and Efficacy of Cardiopulmonary rehabilitation after COVID-19. Am. J. Phys. Med. Rehabil. 2020, 99, 865-869. [CrossRef]

6. Spielmanns, M.; Pekacka-Egli, A.-M.; Schoendorf, S.; Windisch, W.; Hermann, M. Effects of a Comprehensive Pulmonary Rehabilitation in Severe Post-COVID-19 Patients. Int. J. Environ. Res. Public Health 2021, 18, 2695. [CrossRef]

7. Al Chikhanie, Y.; Veale, D.; Schoeffler, M.; Pépin, J.L.; Verges, S.; Hérengt, F. Effectiveness of pulmonary rehabilitation in COVID-19 respiratory failure patients post-ICU. Respir. Physiol. Neurobiol. 2021, 287, 103639. [CrossRef] [PubMed]

8. Betschart, M.; Rezek, S.; Unger, I.; Beyer, S.; Gisi, D.; Shannon, H.; Sieber, C. Feasibility of an Outpatient Training Program after COVID-19. Int. J. Environ. Res. Public Health 2021, 18, 3978. [CrossRef] [PubMed]

9. Vagaggini, B.; Costa, F.; Antonelli, S.; De Simone, C.; De Cusatis, G.; Martino, F.; Santerini, S.; Paggiaro, P. Clinical predictors of the efficiency of a pulmonary rehabilitation programme in patients with COPD. Respir. Med. 2009, 103, 1224-1230. [CrossRef]

10. Scott, A.S.; Baltzan, M.A.; Fox, J.; Wolkove, N. Success in pulmonary rehabilitation in patients with chronic obstructive pulmonary disease. Can. Respir. J. 2010, 17, 219-223. [CrossRef] [PubMed]

11. Enright, P.L.; Sherrill, D.L. Reference equations for the six-minute walk in healthy adults. Am. J. Respir. Crit. Care Med. 1998, 158, 1384-1387. [CrossRef] [PubMed]

12. Cooper, C.B. Exercise in chronic pulmonary disease: Aerobic exercise prescription. Med. Sci. Sports Exerc. 2001, 33, S671-S679. [CrossRef]

13. Borg, G.A. Psychophysical bases of perceived exertion. Med. Sci. Sports Exerc. 1982, 14, 377-381. [CrossRef] [PubMed]

14. ATS. Committee on proficiency standards for clinical pulmonary function laboratories. ATS statement: Guidelines for the six-minute walk test. Am. J. Respir. Crit. Care Med. 2002, 166, 111-117. [CrossRef]

15. Alahdab, M.T.; Mansour, I.N.; Napan, S.; Stamos, T.D. Six minute walk test predicts long-term all-cause mortality and heart failure rehospitalization in African-American patients hospitalized with acute decompensated heart failure. J. Card. Fail. 2009, 15, 130-135. [CrossRef] [PubMed]

16. Boxer, R.; Kleppinger, A.; Ahmad, A.; Annis, K.; Hager, D.; Kenny, A. The 6-minute walk is associated with frailty and predicts mortality in older adults with heart failure. Congest. Heart Fail. 2010, 16, 208-213. [CrossRef]

17. Castel, M.A.; Méndez, F.; Tamborero, D.; Mont, L.; Magnani, S.; Tolosana, J.M.; Berruezo, A.; Godoy, M.; Sitges, M.; Vidal, B.; et al. Six-minute walking test predicts long-term cardiac death in patients who received cardiac resynchronization therapy. Europace 2009, 11, 338-342. [CrossRef]

18. Enfield, K.; Gammon, S.; Floyd, J.; Falt, C.; Patrie, J.; Platts-Mills, T.A.; Truwit, J.D.; Shim, Y.M. Six-minute walk distance in patients with severe end-stage COPD: Association with survival after inpatient pulmonary rehabilitation. J. Car-Diopulm. Rehabil. Prev. 2010, 30, 195-202. [CrossRef]

19. Guyatt, G.H.; Berman, L.B.; Townsend, M.; Pugsley, S.O.; Chambers, L.W. A measure of quality of life for clinical trials in chronic lung disease. Thorax 1987, 42, 773-778. [CrossRef]

20. Linacre, J.M.; Heinemann, A.W.; Wright, B.D.; Granger, C.V.; Hamilton, B.B. The structure and stability of the functional independence measure. Arch. Phys. Med. Rehabil. 1994, 75, 127-132. [CrossRef]

21. Beninato, M.; Gill-Body, K.M.; Salles, S.; Stark, P.C.; Black-Schaffer, R.M.; Stein, J. Determination of the Minimal Clinically Important Difference in the FIM Instrument in Patients With Stroke. Arch. Phys. Med. Rehabil. 2006, 87, 32-39. [CrossRef] [PubMed]

22. Zigmond, A.S.; Snaith, R.P. The Hospital Anxiety and Depression Scale. Acta Psychiatr. Scand. 1983, 67, 361-370. [CrossRef] [PubMed]

23. Osborn, K.; Nothelle, S.; Slaven, J.E. Cumulative illness rating scale (cirs) can be used to predict hospital outcomes in older adults. J. Geriatr. Med. Gerontol. 2017, 3, 30. [CrossRef]

24. Schunemann, H.J.; Griffith, L.; Jaeschke, R.; Goldstein, R.; Stubbing, D.; Guyatt, G.H. Evaluation of the minimal important difference for the feeling thermometer and the St. George's Respiratory Questionnaire in patients with chronic airflow obstruction. J. Clin. Epidemiol. 2003, 56, 1170-1176. [CrossRef]

25. McCormack, M.C.; Bascom, R.; Brandt, M.; Burgos, F.; Butler, S.; Caggiano, C.; Dimmock, A.E.F.; Fineberg, A.; Goldstein, J.; Guzman, F.C.; et al. Electronic Health Records and Pulmonary Function Data: Developing an Interoperability Roadmap. An Official American Thoracic Society Workshop Report. Ann. Am. Thorac. Soc. 2021, 18, 1-11. [CrossRef] 
26. Graham, B.L.; Steenbruggen, I.; Miller, M.R.; Barjaktarevic, I.Z.; Cooper, B.G.; Hall, G.L.; Hallstrand, T.S.; Kaminsky, D.A.; McCarthy, K.; McCormack, M.C.; et al. Standardization of Spirometry 2019 Update. An Official American Thoracic Society and European Respiratory Society Technical Statement. Am. J. Respir. Crit Care Med. 2019, 200, e70-e88. [CrossRef]

27. Davis, M.D.; Walsh, B.K.; Sittig, S.E.; Restrepo, R.D. AARC Clinical Practice Guideline: Blood Gas Analysis and Hemoximetry: 2013. Respir. Care 2013, 58, 1694-1703. [CrossRef]

28. WHO: Clinical Management of COVID-19. Available online: https://www.who.int/publications/i/item/clinical-managementof-COVID-19 (accessed on 18 October 2021).

29. Maniscalco, M.; Fuschillo, S.; Ambrosino, P.; Martucci, M.; Papa, A.; Matera, M.G.; Cazzola, M. Preexisting cardiorespiratory comorbidity does not preclude the success of multidisciplinary rehabilitation in post-COVID-19 patients. Respir. Med. 2021, 184, 106470. [CrossRef] [PubMed]

30. Spruit, M.A.; Holland, A.E.; Singh, S.J.; Tonia, T.; Wilson, K.C.; Troosters, T. COVID-19: Interim Guidance on Rehabilitation in the Hospital and Post-Hospital Phase from a European Respiratory Society and American Thoracic Society-coordinated Inter-national Task Force. Eur. Respir. J. 2020, 56, 2002197. [CrossRef]

31. Li, Z.; Zheng, C.; Duan, C.; Zhang, Y.; Li, Q.; Dou, Z.; Li, J.; Xia, W. Rehabilitation needs of the first cohort of post-acute COVID-19 patients in Hubei, China. Eur. J. Phys. Rehabil. Med. 2020, 56, 339-344. [CrossRef]

32. Kiekens, C.; Boldrini, P.; Andreoli, A.; Avesani, R.; Gamna, F.; Grandi, M.; Lombardi, F.; Lusuardi, M.; Molteni, F.; Perboni, A. Rehabilitation and respiratory management in the acute and early post-acute phase. "Instant paper from the field" on rehabilitation answers to the COVID-19 emergency. Eur. J. Phys. Rehabil. Med. 2020, 56, 323-326. [CrossRef]

33. Rasekaba, T.; Lee, A.L.; Naughton, M.T.; Williams, T.J.; Holland, A.E. The six-minute walk test: A useful metric for the cardiopul-monary patient. Intern. Med. J. 2009, 39, 495-501. [CrossRef]

34. Redelmeier, D.A.; Bayoumi, A.M.; Goldstein, R.S.; Guyatt, G.H. Interpreting small differences in functional status: The Six Minute Walk test in chronic lung disease patients. Am. J. Respir. Crit Care Med. 1997, 155, 1278-1282. [CrossRef]

35. Spielmanns, M.; Gloeckl, R.; Schmoor, C.; Windisch, W.; Storre, J.H.; Boensch, M.; Kenn, K. Effects on pulmonary rehabilitation in patients with COPD or ILD: A retrospective analysis of clinical and functional predictors with particular emphasis on gen-der. Respir. Med. 2016, 113, 8-14. [CrossRef]

36. Skjørten, I.; Ankerstjerne, O.A.W.; Trebinjac, D.; Brønstad, E.; Rasch-Halvorsen, Ø.; Einvik, G.; Lerum, T.V.; Stavem, K.; Edvardsen, A.; Ingul, C.B. Cardiopulmonary exercise capacity and limitations 3 months after COVID-19 hospitalisation. Eur. Respir. J. 2021, 58, 2100996. [CrossRef]

37. Tudoran, C.; Tudoran, M.; Pop, G.N.; Giurgi-Oncu, C.; Cut, T.G.; Lazureanu, V.E.; Oancea, C.; Parv, F.; Ciocarlie, T.; Bende, F. Associations between the Severity of the Post-Acute COVID-19 Syndrome and Echocardiographic Abnormalities in Previously Healthy Outpatients Following Infection with SARS-CoV-2. Biology 2021, 10, 469. [CrossRef]

38. Qin, W.; Chen, S.; Zhang, Y.; Dong, F.; Zhang, Z.; Hu, B.; Zhu, Z.; Li, F.; Wang, X.; Wang, Y.; et al. Diffusion capacity abnormalities for carbon monoxide in patients with COVID-19 at three-month follow-up. Eur. Respir. J. 2021, 58. [CrossRef] [PubMed]

39. Ramalho, S.H.R.; Shah, A.M. Lung function and cardiovascular disease: A link. Trends Cardiovasc. Med. 2021, 31, 93-98. [CrossRef] [PubMed]

40. Bay, M.L.; Pedersen, B.K. Muscle-organ crosstalk: Focus on immunometabolism. Front. Physiol. 2020, 11, 567881. [CrossRef]

41. Huang, Y.; Tan, C.; Wu, J.; Chen, M.; Wang, Z.; Luo, L.; Zhou, X.; Liu, X.; Huang, X.; Yuan, S. Impact of coronavirus disease 2019 on pulmonary function in early convalescence phase. Respir. Res. 2020, 21, 163. [CrossRef] [PubMed]

42. Tudoran, M.; Tudoran, C.; Lazureanu, V.E.; Marinescu, A.R.; Pop, G.N.; Pescariu, A.S.; Enache, A.; Cut, T.G. Alterations of Left Ventricular Function Persisting during Post-Acute COVID-19 in Subjects without Previously Diagnosed Cardiovascular Pathology. J. Pers. Med. 2021, 11, 225. [CrossRef] [PubMed]

43. Carda, S.; Invernizzi, M.; Bavikatte, G.; Bensmail, D.; Bianchi, F.; Deltombe, T.; Draulans, N.; Esquenazi, A.; Francisco, G.E.; Gross, R.; et al. The role of physical and re-habilitation medicine in the COVID-19 pandemic: The clinician's view. Ann. Phys. Rehabil. Med. 2020, 63, 554-556. [CrossRef] 